\section{Accessibility of health and social services}

\section{to immigrant elders: the Islington Study}

\author{
G. LIVINGSTON, G. LEAVEY, G. KITCHEN, M. MANELA, S. SEMBHI \\ and C. KATONA
}

In the UK the small number of ethnic elders ( $\sim 6 \%$ of those aged $\geqslant 65$ years; Office of Population Censuses and Surveys, 1991) are concentrated in deprived inner-city areas and numbers are increasing rapidly as those who migrated after the Second World War to the UK reach retirement age. The idea of multiple jeopardy postulates that ethnic elders, by virtue of age, socio-economic difficulties and minority status, are at greater risk of illness and thus in greater need of health services. In line with this, studies of Asian and Black elders showed that they were more likely to consult their general practitioner (GP) than their UK-born counterparts (Blakemore, 1982; Murray \& Williams, 1986) but were referred less to secondary care health and social services, particularly psychiatric services (Barker, 1984; Manthorpe \& Hettiaratchy, 1993; Bruxner et al, 1997; Leo et al, 1997; Shah \& Dighe-Deo, 1997), although a more recent study of Asian referrals to psychiatric services was not able to confirm this (Odutoye \& Shah, 1999). Several reasons have been suggested for the lack of utilisation of psychiatric services: interpreting symptoms as a spiritual problem (Kleinman, 1987) or a physical illness (Odell et al, 1997); reluctance of ethnic elders to accept referral to secondary mental health services (Shah $e t$ al, 1998); and perceptions by Black people of racism in health workers (Hutchinson \& Gilvarry, 1998). It may be that the medical professional is less able to recognise the presentation of psychological distress by people from other cultures. In this study we aimed to examine differences between the health and service utilisation of older immigrants and their UK-born counterparts and to report whether the differences could be accounted for by subjective or objective health difficulties.

\section{METHOD}

This is a cross-sectional community study of a representative sample of people aged $\geqslant 65$ years in Islington.

\section{Sampling method}

We conducted the survey in Islington, a borough in inner London. The Jarman Underprivileged Area Score is 49, which is the sixth most deprived score in England and Wales (Jarman, 1983). We randomised enumeration districts (the smallest unit of the census) in Islington to provide a sampling frame. The researchers visited each household within those districts, following an introductory letter, to ask if a person aged $\geqslant 65$ years was present and available for interview. Interviewers made at least three visits at different times of the day, or at weekends, until they found the person. All residential facilities in the selected areas were included as part of the sampling frame.

\section{The interview}

We used two standard instruments and additional direct questions during the interview. First, we administered the shortened version of the Comprehensive Assessment and Referral Evaluation (Short-CARE) to elicit psychiatric symptoms and diagnoses (Gurland et al, 1984). This is a valid and reliable questionnaire for older people in the community. It has diagnostic scales for depression and dementia and a scale for activities of daily living (ADL), designed to identify those who need help with dayto-day living. The diagnosis of dementia has been validated against an outcome of deteriorating cognition or death. Validation has been completed cross-nationally but not in specific ethnic groups. The ShortCARE also has a symptom sub-scale measuring somatic symptoms, which records physical symptoms associated with mental health problems, such as dizziness in the absence of loss of consciousness and breathlessness in the absence of exertion or diagnosed physical illness.

Next, we used the Client Service Receipt Inventory (CSRI; Beecham \& Knapp, 1992), amended for use in older people. Items included gender, age, marital status, accommodation, self-designated ethnicity, country of birth, provision of health and social services and family and friends coming in to provide help in the past 3 months. To classify ethnicity, the interviewers showed the list of ethnic classification in the 1991 census and asked the participants to choose what best described them.

Finally, we asked 'Do you have any health problems?' as a screening question 
for subjective health problems. If the answer was 'yes', a further question was asked: 'Can you tell me what they are?' The answers were noted and a nurse or doctor categorised them for analysis (e.g. cardiovascular, psychiatric, gastrointestinal).

\section{Analysis}

For the purposes of analysis, country of birth and ethnicity were recoded to increase the numbers in each category. The countries of birth were aggregated into six categories: UK; Ireland; Cyprus; African and Caribbean; other European; and others.

Owing to the large numbers of itemised health care services, we analysed service utilisation in the following areas: (a) GP; (b) hospital medical services (nonpsychiatric in-patient, day patient or outpatient); (c) hospital out-patient services (non-psychiatric day patient or outpatient); (d) psychiatric contact (psychiatric in-patient, out-patient, community psychiatric nurse, domiciliary visit from psychiatrist, psychology contact); (e) nonmedical health care (dietician, physiotherapist, occupational therapist or chiropodist); (f) day care services (day centre, lunch club or domiciliary respite service); (g) other social services (social worker, home care and meals on wheels); (h) informal care (non-resident family, friends or voluntary services).

We used $\chi^{2}$ analysis to test for significant associations in categorical data. We calculated the numbers, percentage, probability, relative risk (RR) and $95 \%$ confidence interval (CI) of people from each country of birth in contact with different services compared with the UK-born group. For non-parametric data we used the MannWhitney $U$-test to examine associations between ordinal and categorical variables.

Older immigrants from African and Caribbean countries and those born in Cyprus have raised rates of particular neuropsychiatric conditions (Livingston et al, 2001). We therefore considered the elders born in African and Caribbean countries and in Cyprus in forward logistic regression analyses, to consider whether such conditions accounted for any differential use of services within those immigrant groups. The other variables entered in the regression analyses were depression, dementia, age, gender, living alone, ADL limitation and having subjective health problems. Significant independent predictors and the odds ratio (OR) with $95 \% \mathrm{CI}$ are reported.

\section{RESULTS}

\section{Demography}

We interviewed 1085 older people $(85.3 \%$ response rate), of whom $644 \quad(59.4 \%)$ were female. Their ages ranged from 65 to 102 years. Ninety-five per cent (1031) of the people lived in their own homes and the other $5 \%$ lived in accommodation with around-the-clock staffing.

\section{Non-participants}

Of the 197 people who did not participate in the study, $153(77.7 \%)$ refused an interview, an interpreter was unavailable for 15 $(7.6 \%), 11(5.6 \%)$ relatives refused on behalf of the older person and 2 had difficulty communicating $(1.3 \%) ; 64.3 \%$ of the nonparticipants were female.

\section{Ethnicity and country of birth}

Table 1 shows the self-assigned ethnicities and countries of birth of the respondents. In total, the respondents had 50 different countries of birth. Five people declined to choose any of the listed ethnicities and 93 (95\%) of those born in African or Caribbean countries were Black. Because there are few differences between country of birth and ethnicity, the remainder of the paper will report only country of birth in order to avoid repetition.

\section{Morbidity}

Table 2 shows morbidity according to country of birth and ethnicity. The Cypriots

Table I Self-designated ethnicity and country of birth

\begin{tabular}{lclc}
\hline Self-designated ethnicity & No. (\%) & Country of birth & No. (\%) \\
\hline White British & $703(64.8)$ & Britain & $666(61.4)$ \\
Irish & $125(11.5)$ & Ireland & $139(12.8)$ \\
Greek Cypriot & $60(5.5)$ & Greece, Cyprus, Turkey & $72(6.6)$ \\
Turkish Cypriot & $8(0.7)$ & & $98(9.1)$ \\
Black African & $10(0.9)$ & Africa, Caribbean & \\
Black Caribbean & $60(5.5)$ & & $60(5.5)$ \\
Black British & $25(2.3)$ & & $50(4.6)$ \\
Black others & $2(0.2)$ & & Europe \\
White others & $61(5.6)$ & Other countries & \\
Asian & $16(1.5)$ & & \\
Indian & $8(0.7)$ & & \\
Bangladeshi & 1 & \\
Chinese & 1 & \\
Total & 10801 & \\
\hline I. & & & \\
\hline
\end{tabular}

I. Five people did not designate their ethnicity. were significantly more depressed and had higher subjective morbidity than their UKborn counterparts but were no more likely to have limitation in ADL. The number of ranged from 0 to $13(2(0.2 \%)$ and 352 $(32.4 \%)$ individuals respectively). The median number of somatic symptoms recorded was two. Cypriots were the only immigrant population to report significantly more somatic symptoms than those born in the UK (Mann-Whitney $U=18940.500 ; P=0.005$ ).

\section{Service utilisation}

Table 3 shows the use of services in the 3 months before interview and the association with different countries of birth.

\section{General practitioner services}

Both the likelihood of visiting a GP (overall $\left.\chi^{2}=16.1 ; P<0.006\right)$ and the frequency of visits to the GP (overall $\chi^{2}=88.2$; $P<0.0002)$ differed significantly according to country of birth. Those born in the UK were least likely and Cypriot immigrants most likely to have seen their GP $(55.0 \%$ v. $74.6 \%$ ) over the 3 months prior to interview. We used logistic regression analysis to find independent predictors of contact with the GP. These were: subjective health problem $(P<0.001 ;$ OR $=3.57 ; 95 \%$ CI 2.46-5.19); being born in Cyprus $(P<0.05$; $\mathrm{OR}=1.95$; 95\% CI 1.11-3.42); depression $(P<0.05 ;$ OR $=1.47 ; 95 \%$ CI $1.04-2.06)$; and dementia (negative correlation) $(P<0.005 ;$ OR $=0.54 ; 95 \%$ CI $0.35-0.83)$. somatic symptoms reported by individuals 
Table 2 Morbidity according to country of birth ( $\mathrm{ADL}=$ activities of daily living)

\begin{tabular}{|c|c|c|c|c|c|c|c|c|c|c|c|c|}
\hline \multirow[t]{3}{*}{ Country of birth } & \multicolumn{2}{|c|}{ Dementia } & \multirow{3}{*}{$\begin{array}{c}\text { RR } \\
(95 \% \mathrm{Cl})\end{array}$} & \multicolumn{2}{|c|}{ Depression } & \multirow{3}{*}{$\begin{array}{c}\mathrm{RR} \\
(95 \% \mathrm{Cl})\end{array}$} & \multicolumn{2}{|c|}{ ADL limitation } & \multirow{3}{*}{$\begin{array}{c}\mathrm{RR} \\
(95 \% \mathrm{Cl})\end{array}$} & \multirow{2}{*}{\multicolumn{2}{|c|}{$\begin{array}{c}\text { Subjective health } \\
\text { problem }\end{array}$}} & \multirow{3}{*}{$\begin{array}{c}\mathrm{RR} \\
(95 \% \mathrm{Cl})\end{array}$} \\
\hline & \multirow{2}{*}{$n$} & \multirow{2}{*}{ (\%) } & & \multirow{2}{*}{$n$} & \multirow{2}{*}{$(\%)$} & & \multirow{2}{*}{$n$} & \multirow{2}{*}{ (\%) } & & & & \\
\hline & & & & & & & & & & $n$ & (\%) & \\
\hline UK & 67 & $(10.1)$ & 1.00 & 120 & $(18.0)$ & 1.00 & 288 & $(43.2)$ & 1.00 & 574 & $(86.2)$ & 1.00 \\
\hline Ireland & 5 & (3.6) & $\begin{array}{c}0.36 \\
(0.15-0.87)^{*}\end{array}$ & 23 & $(16.5)$ & $\begin{array}{c}0.92 \\
(0.61-1.38)\end{array}$ & 49 & $(35.3)$ & $\begin{array}{c}0.7 \\
(0.5-1.0)\end{array}$ & III & $(81.0)$ & $\begin{array}{c}0.68 \\
(0.42-I . I I)\end{array}$ \\
\hline Greece, Turkey, Cyprus & 8 & (II.I) & $\begin{array}{c}1.10 \\
(0.55-2.21)\end{array}$ & 20 & $(27.8)^{*}$ & $\begin{array}{c}1.54 \\
(I .03-2.3 I)\end{array}$ & 35 & $(48.6)$ & $\begin{array}{c}1.2 \\
(0.8-2.0)\end{array}$ & 67 & $(94.4)^{*}$ & $\begin{array}{c}2.68 \\
(0.96-7.54)\end{array}$ \\
\hline Africa, Caribbean & 17 & (I7.3) & $\begin{array}{c}1.72 \\
(1.06-2.8 I)^{*}\end{array}$ & 14 & $(14.3)$ & $\begin{array}{c}0.79 \\
(0.48-1.32)\end{array}$ & 50 & $(51.0)$ & $\begin{array}{c}1.4 \\
(0.9-2.1)\end{array}$ & 87 & (88.8) & $\begin{array}{c}1.27 \\
(0.65-2.47)\end{array}$ \\
\hline Europe & 5 & (8.3) & $\begin{array}{c}0.83 \\
(0.35-1.98)\end{array}$ & II & (18.3) & $\begin{array}{c}1.02 \\
(0.58-\mid .78)\end{array}$ & 24 & $(40.0)$ & $\begin{array}{c}0.9 \\
(0.5-1.5)\end{array}$ & 49 & (8I.7) & $\begin{array}{c}0.97 \\
(0.36-1.42)\end{array}$ \\
\hline Other & 5 & $(10.0)$ & $\begin{array}{c}0.99 \\
(0.42-2.35)\end{array}$ & II & $(22.0)$ & $\begin{array}{c}1.22 \\
(0.7 I-2 . I I)\end{array}$ & 24 & $(48.0)$ & $\begin{array}{c}1.2 \\
(0.7-2.2)\end{array}$ & 42 & $(84.0)$ & $\begin{array}{c}0.84 \\
(0.35-1.85)\end{array}$ \\
\hline Total & 107 & $(9.9)$ & & 199 & $(18.3)$ & & 470 & $(43.3)$ & & 930 & $(86.0)$ & \\
\hline
\end{tabular}

$* P<0.05$

Table 3 Contact (\%) with service by country of birth: significance, relative risk and confidence intervals compared with UK-born population

\begin{tabular}{|c|c|c|c|c|c|c|c|c|}
\hline $\begin{array}{l}\text { Country of birth } \\
\text { (n) }\end{array}$ & $\begin{array}{c}\text { General } \\
\text { practitioner visit }\end{array}$ & $\begin{array}{l}\text { Out-patient } \\
\text { services }\end{array}$ & $\begin{array}{c}\text { Hospital medical } \\
\text { services }\end{array}$ & $\begin{array}{l}\text { Psychiatric } \\
\text { services }\end{array}$ & $\begin{array}{l}\text { Non-medical } \\
\text { health care }\end{array}$ & Day services & $\begin{array}{l}\text { Other social } \\
\text { services }\end{array}$ & Informal care \\
\hline \multirow[t]{2}{*}{ Britain (666) } & $366(55.0)$ & $214(32.1)$ & $232(34.8)$ & $15(2.3)$ & $83(12.4)$ & $46(6.9)$ & $102(15.3)$ & $433(65.0)$ \\
\hline & $R R=I$ & $R R=I$ & $R R=I$ & $R R=I$ & $R R=I$ & $\mathrm{RR}=\mathrm{I}$ & $R R=I$ & $R R=I$ \\
\hline \multirow[t]{3}{*}{ Ireland (139) } & $90(64.7)^{*}$ & $5 \mathrm{I}(36.7)$ & $5 I(36.7)$ & $2(1.4)$ & $24(17.3)$ & $5(3.6)$ & $14(10.1)$ & $100(71.9)$ \\
\hline & 1.51 & 1.22 & 1.08 & 0.63 & $\mathrm{I} .47$ & 0.50 & 0.62 & I.3I \\
\hline & $(1.03-2.20)$ & $(0.84-1.79)$ & $(0.74-1.59)$ & $(0.14-2.80)$ & $(0.89-2.4 I)$ & $(0.20-1.29)$ & $(0.34-1.12)$ & $(0.93-1.84)$ \\
\hline Greece, Turkey, & $53(74.6)^{* *}$ & 31 (43.7)* & 34 (47.9)* & 0 & $6(8.5)$ & $5(6.9)$ & $10(14.1)$ & $37(52.1)^{*}$ \\
\hline \multirow[t]{2}{*}{ Cyprus (72) } & 2.41 & 1.64 & 1.72 & 0.90 & 0.65 & 1.02 & 0.91 & 0.62 \\
\hline & $(1.38-4.20)$ & $(1.00-2.69)$ & $(1.05-2.81)$ & $(0.88-0.92)$ & $(0.27-1.55)$ & $(0.39-2.66)$ & $0.45-1.83$ & $(0.40-0.96)$ \\
\hline Africa, & $62(63.3)$ & $37\left(37.8^{*}\right)$ & 37 (37.8) & 2 (20.9) & $10(10.2)$ & $13(13.3)^{*}$ & $21(2 l .4)$ & $53(54 . I)^{*}$ \\
\hline \multirow[t]{2}{*}{ Caribbean (98) } & I.4I & I.14 & 1.28 & 0.90 & 0.90 & 2.06 & I.5I & 0.67 \\
\hline & $(0.91-2.19)$ & $(0.73-1.76)$ & $(0.83-1.99)$ & $(0.20-4.02)$ & $(0.40-1.59)$ & $(1.13-3.97)$ & $(0.89-2.55)$ & $(0.47-0.97)$ \\
\hline \multirow[t]{3}{*}{ Europe (60) } & $38(64.4)$ & $21(35.6)$ & $19(32.2)$ & 0 & $7(7.8)$ & $2(3.4)$ & $8(13.3)$ & $40(66.7)$ \\
\hline & 1.48 & 1.18 & 0.89 & 0.98 & 0.95 & 0.47 & 0.85 & 1.07 \\
\hline & $(0.85-2.58)$ & $(0.68-2.07)$ & $(0.50-1.57)$ & $(0.97-0.99)$ & $(0.42-2.16)$ & $(0.11-2.00)$ & $(0.39-1.84)$ & $(0.64-1.79)$ \\
\hline \multirow[t]{3}{*}{ Other (50) } & $32(64.0)$ & I4 (28.0) & $16(32.0)$ & $2(4.0)$ & $6(12.0)$ & $4(8.0)$ & $8(16.0)$ & $26(52.0)$ \\
\hline & 1.46 & 0.82 & 0.88 & 1.81 & 0.96 & 1.17 & 1.05 & 0.60 \\
\hline & $(0.80-2.65)$ & $(0.43-1.55)$ & $(0.48-1.63)$ & $(0.40-8.14)$ & $(0.40-2.32)$ & $(0.40-3.40)$ & $(0.48-2.31)$ & $(0.36-1.03)$ \\
\hline Total (1085) & $64 \mid(59.2)$ & $336(33.8)$ & & $20(1.9)$ & & 75 (6.9) & $163(15.0)$ & $689(63.6)$ \\
\hline
\end{tabular}

$* P<0.05 ; * * P<0.005 ; * * * P<0.001$.

\section{Hospital services}

The use of secondary care medical services varied significantly according to the country of birth. Cypriots were significantly more likely to use these services than their UK-born counterparts. Searching for predictors of contact with hospital medical services using logistic regression analysis, we identified subjective health problem $(P<0.001 ; \quad O R=4.01 ; 95 \%$ CI 2.39-6.90), limitation in physical activity $(P<0.001 ; \quad O R=2.00 ; \quad 95 \%$ CI $1.52-$ 2.63) and dementia (negative correlation) $(P<0.001 ; \quad$ OR $=0.39 ; \quad 95 \% \quad$ CI $\quad 0.24$ $0.66)$.

\section{Social services}

Africans and Caribbeans used day care and other social services most frequently. We found, using logistic regression, that living alone was the strongest predictor of the use of day services $(P<0.001$; OR $=2.89$; $95 \%$ CI 1.69-4.94), followed by having 
dementia $(P<0.007 ;$ OR $=2.57 ; 95 \%$ CI 1.31-5.11). Other predictors were African or Caribbean country of birth $(P<0.02$; $\mathrm{OR}=2.28$; 95\% CI 1.16-4.44), depression $(P<0.02 ; \mathrm{OR}=2.00 ; 95 \%$ CI $1.16-3.40)$, ADL limitation $(P<0.05 ; \mathrm{OR}=1.75 ; 95 \%$ CI 1.03-3.00) and female gender $(P<0.05 ; \mathrm{OR}=1.82 ; 95 \%$ CI $1.03-3.16)$. Predictors of other social service use were ADL limitation $(P<0.001 ; \quad O R=11.05$; $95 \% \quad$ CI 6.74-17.84), living alone $(P<0.001 ; \quad O R=3.36 ; \quad 95 \% \quad$ CI $2.23-$ $4.88)$, African or Caribbean country of birth $(P<0.03$; OR $=1.93$; 95\% CI $1.07-$ 3.47) and increasing age $(P<0.001$; $\mathrm{OR}=1.06$; $95 \%$ CI 1.03-1.09 for each year increase).

Cypriots and African and Caribbean respondents received less informal care than their UK-born counterparts. In logistic regression analyses of predictors of receipt of informal care, the only significant predictors that remained were ADL limitation $(\mathrm{OR}=5.67 ; P<0.001 ; 95 \%$ CI 4.23-7.58), subjective health problems $(\mathrm{OR}=2.50$; 95\% CI 1.51-4.14; $P<0.0001)$, depression $(\mathrm{OR}=1.9 ; 95 \%$ CI $1.34-2.70 ; P<0.001)$ and older age $(\mathrm{OR}$ for 1 year increase $=1.02 ; \quad 95 \% \quad$ CI $1.01-4.14$; $P<0.02$ ).

\section{Psychotropic medication}

Table 4 shows those taking psychotropic medication. This did not vary significantly according to country of birth, although those born in Cyprus took psychotropics less than those born in any other country. Taking psychotropic medication was associated significantly with contact with psychiatric services: $14(73.6 \%)$ of those in contact with services $v .137(14.8 \%)$ of those not $(P<0.001, \mathrm{RR}=18.91 ; 95 \% \mathrm{CI}$ 6.70-53.31). Most people (34/42) taking antipsychotics said that they had not been in contact with psychiatric services in the past 3 months, as did most of those taking antidementia drugs (3/4).

\section{DISCUSSION}

This is the first epidemiological study in the UK to examine the use of health, social and informal services by immigrant elders compared with the UK-born population. Our main findings indicate that immigrants in general accessed primary and secondary health care and social care services at least at the same level as older UK-born people. Although we found no significant differences in the physical health of immigrant groups compared with the UK-born, Africans and Caribbeans appear to have poorer physical health and this excess morbidity accounts for their greater contact with health and social services.

\section{The Cypriot community}

The highest rates of medical service use were by the Cypriot-born. This group also was most likely to experience depression and reported most somatic symptoms. They did not admit to using psychiatric services at all and were least likely to be taking psychotropic medication. They had the worst subjective health problems although they were not the most physically ill. Neither the physical, psychiatric and subjective health problems nor the socioeconomic factors accounted for the increased contact with the GP. In contrast, contact with hospital medical services appears to have been accounted for by worse subjective physical health. Those born in Cyprus who experience depression may present with prominent somatic symptoms that may be misdiagnosed as having a physical basis (or confused with physical illness). This is likely to be due to a different idiom of distress and to be a culturally sanctioned presentation.
Earlier studies of morbidity in younger Greek-Cypriot immigrants in London found that this population was relatively upwardly mobile and affluent (Mavreas \& Bebbington, 1987). There were higher rates of affective disorders compared with the local population but the rates were similar to those found in Athens, suggesting a cultural aetiology rather than the stress of immigration. There was, in particular, an increased rate of overall psychiatric disorders in those suffering from any physical illness. Those who had migrated more than 20 years previously had changed less and were less likely to speak English. Knowledge of English was found to protect against psychiatric disorder (Mavreas \& Bebbington, 1989, 1990).

Our study confirms the pattern of high rates of depression in an older population that did not have the usual risk factors of being alone, isolated or of relatively low socio-economic status. A predominant somatic presentation has been reported in other cultures and should be considered particularly in those who are from minority immigrant groups (Patel et al, 2001).

\section{Limitations of the study}

Our study relied on participants' self-report of their contact with services (or that of carers, if the person had dementia). Our researchers looked at the bottles of medication and thus we were confident about what people were taking. When psychotropic medication consumption is considered, it suggests that there was an underreporting of contact with psychiatric services.

The results suggest that older people were not in receipt of the appropriate psychiatric services, yet we have evidence to suggest that this is an inaccurate picture. At the time the data were gathered, local services had just started prescribing

Table 4 Psychotropic drug use by country of birth $(n, \%$, relative risk, $95 \% \mathrm{Cl})$

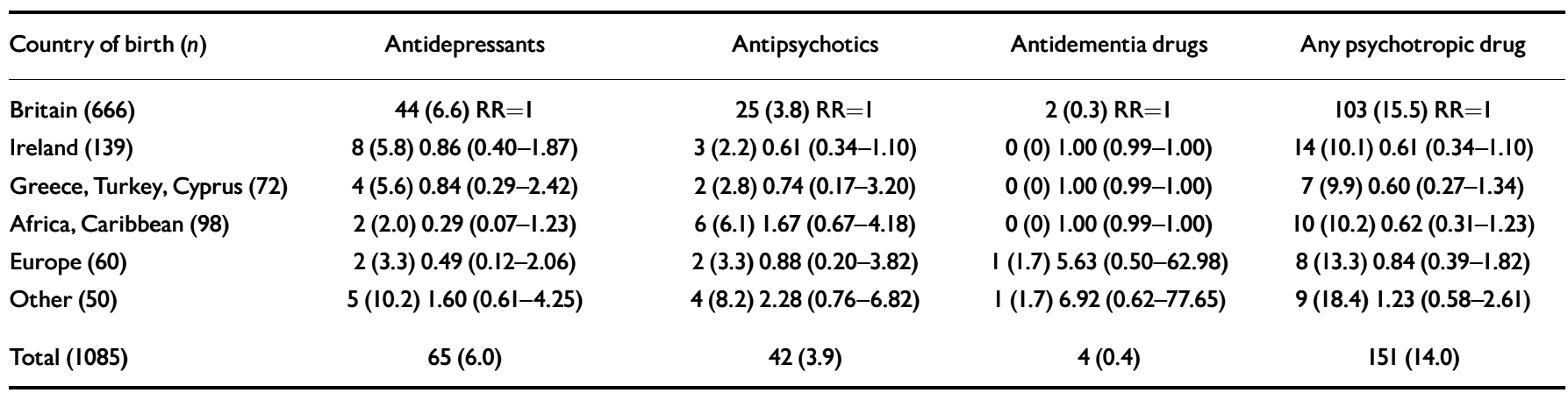


antidementia drugs and all patients should have had a 3-monthly follow-up by a psychiatrist. Despite this, most of the people taking cholinesterase inhibitors or antipsychotics reported that they had not had psychiatric contact. This underreporting suggests that the use of psychiatric services by older people remains stigmatised.

Although our study was designed to ensure that we interviewed a representative population using instruments with appropriate psychometric properties, it was in a relatively deprived inner-city area with a relatively large immigrant population. Within inner London there is the presence of health and welfare professionals from a diverse range of ethnic and cultural backgrounds who may be expected to have an awareness of issues pertinent to these groups. We cannot therefore generalise the findings to dissimilar populations.

Informal care was measured by asking about relatives and friends coming in to help with the ADL. We did not measure what spouses and carers did for their patients because it was difficult to define care in a family context. Our measure of informal help is therefore flawed, as spouses probably provide the most care.

\section{ACKNOWLEDGEMENTS}

We would like to thank the people of Islington for welcoming our researchers into their homes and answering numerous questions.

\section{REFERENCES}

Barker, J. (1984) Research Perspectives on Ageing: Black and Asian Old People in Britain. London: Age Concern Research Unit.

Beecham, J. \& Knapp, M. (1992) Costing psychiatric interventions. In Measuring Mental Health Needs (eds G. Thornicroft, C. R. Brewin \& J.Wing), pp. 163-183. London: Gaskell.

Blakemore, K. (1982) Health and illness among the elderly of minority ethnic groups living in Birmingham: some new findings. Health Trends, 14, 69-72.

Bruxner, G., Burvill, P. \& Fazio, S. (1997) Aspects of psychiatric admissions of migrants to hospitals in Perth Australian and New Zealand Journal of Psychiatry, 31, 532-542.

Gurland, B., Golden, R., Teresi, J. A., et al (1984) The Short-CARE. An efficient instrument for the assessment of depression and dementia. Journal of Gerontology, 39, 166-169.

Hutchinson, G. \& Gilvarry, C. (1998) Ethnicity and dissatisfaction with mental health services. British Journal of Psychiatry, 172, 95-96.

Jarman, B. (1983) Identification of underprivileged areas. BMJ, 286, 1705-1709.

\section{CLINICAL IMPLICATIONS}

Elderly immigrants access primary and secondary health care and social care services.

- Those born in Cyprus who experience depression may present with prominent somatic symptoms that may be misdiagnosed as having a physical basis (or confused with physical illness). This is likely to be due to a different idiom of distress and to be a culturally sanctioned presentation.

- There is an underreporting of contact with psychiatric service, suggesting continued stigma.

\section{LIMITATIONS}

- Our study relied on participants' self-report of their contact with services (or that of carers, if the person had dementia).

- Our study was of a deprived inner-city area with a large immigrant population. We cannot generalise the findings to dissimilar populations.

- Informal care was measured by relatives and friends coming in to help and was not a measure of spouse help.

G. LIVINGSTON, FRCPsych, Department of Psychiatry and Behavioural Sciences, Royal Free and University Medical School, London; G. LEAVEY, MSc, St Ann's Hospital, London; G. KITCHEN, RMN, M. MANELA, MBChir, S. SEMBHI, MRCPsych, C. KATONA, FRCPsych, Department of Psychiatry and Behavioural Sciences, Royal Free and University College Medical School, London

Correspondence: G. Livingston, Department of Psychiatry and Behavioural Sciences, Royal Free and University College Medical School,Wolfson Building, 48 Riding House Street, London WIN 8AA, UK. Tel: 0207530 2309; fax: 02075302304 ; e-mail: g. livingston@ucl.ac.uk

(First received 20 June 200I, final revision 7 January 2002, accepted 14 January 2002)

Kleinman, A. (1987) Depression, somatisation and the 'new cross-cultural psychiatry'. Social Science and Medicine, II, 3-10.

Knapp, M. (1985) The Economic Evaluation of Mental Health Care. Aldershot: Arena.

Leo, R. J., Narayan, D. A., Sherry, C., et al (1997) Geropsychiatric consultation for African-American and Caucasian patients. General Hospital Psychiatry, 19, $216-222$

Livingston, G., Leavey, G., Kitchen, G., et al (200I) Mental health of migrant elders: the Islington Study. British Journal of Psychiatry, 179, 361-366.

Mavreas, V. \& Bebbington, P. (1987) Psychiatric morbidity in London's Greek-Cypriot immigrant community. I. Associations with sociodemographic variables. Social Psychiatry, 22, 150-159.

_ \& _ (1989) Does the act of migration provoke psychiatric breakdown? A study of Greek Cypriot immigrants. Acta Psychiatrica Scandinavica, 80 469-473.

— \& _ (1990) Acculturation and psychiatric disorder: a study of Greek Cypriot immigrants. Psychological Medicine, 20 (4), 94I-95।.

Manthorpe, J. \& Hettiaratchy, P. (1993) Ethnic minority elders in the UK. International Review of Psychiatry, 5, 17I-178.
Murray, J. \& Williams, P. (1986) Self-reported illness and general practice consultations in Asian-born and British-born residents of West London. Social Psychiatry, 2I, 139-145.

Odell, S. M., Surtees, P. G., Wainwright, N.W. J., et al (1997) Determinants of general practitioner recognition of psychological problems in a multi-ethnic inner-city health district. British Journal of Psychiatry, 17I, 537-54I.

Odutoye, K. \& Shah, A. (1999) The characteristics of Indian subcontinent origin elders newly referred to a psychogeriatric service. International Journal of Geriatric Psychiatry, 14, 446-453.

Office of Population Censuses and Surveys (1991) Census of Ethnic Group and Country of Birth. London: OPCS.

Patel, V., Abas, M., Broadhead, J., et al (200I) Depression in developing countries: lessons from Zimbabwe. BMJ, 322, 483-484.

Shah, A. K. \& Dighe-Deo, D. (1997) Elderly Gujaratis and psychogeriatrics in a London psychogeriatric service. Bulletin of the International Psychogeriatric Association, 14, 12-13.

_ , Lindesay, J. \& Jaggar, C. (1998) Is the diagnosis of dementia stable over time among elderly immigrant Gujeratis in the United Kingdom? International Journal of Psychiatry, 13, 440-444. 